\title{
Mechanical Properties of Harmonic Structured Composite with Pure Titanium and Ti-48 at\% Al Alloy by MM/SPS Process
}

\author{
Hiroshi Fujiwara ${ }^{1, *}$, Takeshi Kawabata ${ }^{2}$, Hiroyuki Miyamoto ${ }^{1}$ and Kei Ameyama ${ }^{3}$ \\ ${ }^{1}$ Department of Mechanical and Systems Engineering, Doshisha University, Kyotanabe 610-0394, Japan \\ ${ }^{2}$ Graduate School, Doshisha University, Kyotanabe 610-0394, Japan \\ ${ }^{3}$ Department of Mechanical Engineering, Ritsumeikan University, Kusatsu 525-8577, Japan
}

\begin{abstract}
Ti-Al alloy demonstrates high strength in high-temperature environments. Thus, the Ti-Al alloys are expected in an application as high temperature materials. However, the Ti-Al alloys demonstrate low strength and limited ductility at room temperature. Harmonic-structured materials with a network fine grain structure and a dispersed coarse grain structure show high strength and sufficient ductility at room temperature. In addition, a composite of different materials is also effective in improving both strength and ductility. Therefore, the harmonicstructured composite with pure titanium (Ti) and $\mathrm{Ti}-48$ at\% Al alloy ( $\mathrm{Ti}-48 \mathrm{Al}$ ) were fabricated by the combination of the mechanical milling $(\mathrm{MM})$ and the spark plasma sintering (SPS) process. The harmonic-structured composite has a fine grained network Ti-Al alloy and a dispersed coarse grain Ti region. The XRD result reveals that the harmonic-structured composite composes of $\mathrm{Ti}_{\text {, }} \mathrm{TiAl}_{\mathrm{And}} \mathrm{Ti}_{3} \mathrm{Al}$ phases. The harmonicstructured composite demonstrates high strength and sufficient ductility compared with the conventional compact consisting of only Ti-48Al. Advanced ductility of the harmonic-structured composite is attributed to an obstruction of the crack propagation by the dispersed coarse grain region. After heat treatment of the $\mathrm{Ti} / \mathrm{Ti}-48 \mathrm{Al}$ harmonic-structured composite, its hardness decreased to much lesser than that of the pure $\mathrm{Ti}$ compact. [doi:10.2320/matertrans.MH201317]
\end{abstract}

(Received March 6, 2013; Accepted April 8, 2013; Published May 17, 2013)

Keywords: harmonic structure, titanium-aluminum alloy, pure titanium, mechanical milling, spark plasma sintering

\section{Introduction}

Ti-Al alloys demonstrate high strength in high-temperature environments; thus, they are used in turbochargers and are expected to find use in other applications such as in jet engines. ${ }^{1-3)}$ However, the range of Ti-Al alloy applicability is limited, because it has low strength and a limited ductility at room temperature. ${ }^{4,5}$ It is well known that a grain refinement is an effective method for improving both the strength and ductility of such alloys. However, ultra finegrained materials (i.e., with homogeneous nano grains) demonstrate high strength but low ductility because of early plastic instability. ${ }^{6,7)}$ On the other hand, a harmonicstructured material with a networked fine grain area and a dispersed coarse grain area shows high strength and sufficient ductility. ${ }^{8-11)}$ In addition, a composite of different materials is also effective in improving both strength and ductility. A composite with $\mathrm{TiAl}$ and $\mathrm{Ti}_{2} \mathrm{AlC}$ phases demonstrates a higher strength and elongation than TiAl-phase material. ${ }^{12)}$ Therefore, to improve the mechanical properties of $\mathrm{Ti}-\mathrm{Al}$ alloys at room temperature, a harmonic-structured composite consisting of a $\mathrm{Ti}-\mathrm{Al}$ alloy and pure titanium was fabricated by mechanical milling (MM) and spark plasma sintering (SPS) process and its mechanical properties were evaluated in detail.

\section{Experimental Procedure}

Powders of titanium alloyed with 48 at $\% \mathrm{Al}$ (Ti-48Al) and commercially pure titanium (Ti; 99.9 mass $\%$ purity) were used in this study. The initial particle sizes of the Ti-48Al and the pure $\mathrm{Ti}$ powders were about 260 and $200 \mu \mathrm{m}$, respectively. These powders were mechanically milled using

*Corresponding author, E-mail: hifujiwa@mail.doshisha.ac.jp

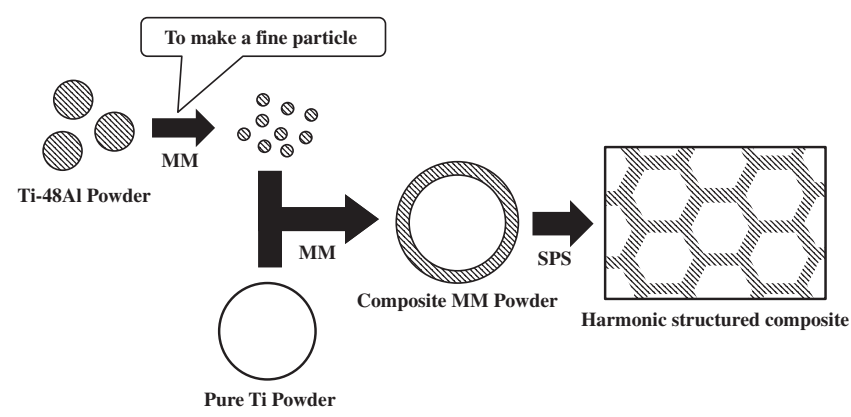

Fig. 1 Schematic of the process to fabricate the harmonic-structured composite by MM/SPS process.

planetary ball mill equipment (P-6; Fritch Co., Ltd.) with an SKD11 vial and SUJ2 steel balls in Ar atmosphere at room temperature. First, to obtain a fine $\mathrm{Ti}-48 \mathrm{Al}$ powder, mechanical milling was performed at a ball-to-powder weight ratio of $3: 1$ and an MM time of $54 \mathrm{ks}$. Next, a mixture of pure $\mathrm{Ti}$ powder and $\mathrm{Ti}-48 \mathrm{Al}$ (11.1 to 20.0 mass\%) $\mathrm{MM}$ powder was mechanically milled at a ball-to-powder weight ratio of 2:1 and an MM time of $36 \mathrm{ks}$. The composite MM powder containing $\mathrm{Ti}-48 \mathrm{Al}$ and pure $\mathrm{Ti}$ was sintered using SPS apparatus (SPS-510L; Sumitomo Coal Mining Co., Ltd.) at $1073 \mathrm{~K}$ and $50 \mathrm{MPa}$ for $1.8 \mathrm{ks}$. Figure 1 shows a schematic of the process to fabricate the composite MM compact by MM and SPS. Scanning electron microscopy (SEM)/energy dispersive X-ray spectroscopy (EDS) and X-ray diffraction (XRD) were employed to observe the microstructure of the composite SPS compact with $\mathrm{Ti}-48 \mathrm{Al}$ and pure Ti. The mechanical properties of the composite SPS compacts were evaluated by the Vickers hardness test (VMT-7; Matsuzawa Co., Ltd.) and a tensile test (AGS-10kND; Shimadzu Corporation) with an initial strain rate of $5.5 \times 10^{-4} \mathrm{~s}^{-1}$. 


\section{Results and Discussions}

The Ti-48Al powder was refined to about $80.5 \mu \mathrm{m}$ by MM for $54 \mathrm{ks}$. The composite MM powder in which pure Ti and $\mathrm{Ti}-48 \mathrm{Al}$ fine powders were combined by MM for $36 \mathrm{ks}$ is shown in Fig. 2. Figures 2(a) and 2(b) show SEM micrographs of the appearance and the cross section of the composite MM powder with Ti-48Al (20.0 mass\%), respectively. Figures 2(c) and 2(d) indicate EDS results for the $\mathrm{Al}$ and $\mathrm{Ti}$ concentrations shown in Fig. 2(b), respectively. The composite MM powder shown in Fig. 2(b) exhibits a different contrast in the surface and middle regions, and Figs. 2(c) and 2(d) demonstrate that the surface region has high $\mathrm{Al}$ concentration. Figure 3 shows the XRD result for the composite MM powder with $\mathrm{Ti}-48 \mathrm{Al}$ (20.0 mass\%). The composite MM powder consists of $\mathrm{Ti}$, TiAl and $\mathrm{Ti}_{3} \mathrm{Al}$ phases. Therefore, the surface region in Fig. 2(b) corresponds to a $\mathrm{Ti}-\mathrm{Al}$ alloy with the $\mathrm{TiAl}$ and $\mathrm{Ti}_{3} \mathrm{Al}$ phases and the middle region corresponds to the $\mathrm{Ti}$ phase.

The composite MM powder as shown in Fig. 2 was sintered using an SPS apparatus, and an interesting microstructure was obtained. Figure 4 shows this microstructure in an SEM micrograph of a $\mathrm{Ti} / \mathrm{Ti}-48 \mathrm{Al}$ composite compact with 14.3 mass $\% \mathrm{Ti}-48 \mathrm{Al}$ sintered at $1073 \mathrm{~K}$ for $1.8 \mathrm{ks}$. This micrograph has a network structure, and its network region corresponds to the surface region of the composite MM powder shown in Fig. 2; that is, the network structure is composed of a Ti-Al alloy. The dispersed region surrounding the network corresponds to pure Ti material. A microstructure having network and dispersed regions is referred to as a "harmonic structure". Figure 5 shows the XRD result for the harmonic-structured composite shown in Fig. 4. This harmonic-structured composite consists of $\mathrm{Ti}$, TiAl and $\mathrm{Ti}_{3} \mathrm{Al}$ phases, and the network $\mathrm{Ti}-\mathrm{Al}$ alloy region consists of $\mathrm{TiAl}$ and $\mathrm{Ti}_{3} \mathrm{Al}$ phases. Figures $6(\mathrm{a})$ and $6(\mathrm{~b})$ show SEM micrographs of the network and dispersed regions of the harmonicstructured composite, respectively. As shown in Fig. 6(a), a lamellar structure with a width of several tens of nanometers is observed in the network $\mathrm{Ti}-\mathrm{Al}$ alloy region and consists of $\mathrm{TiAl}$ and $\mathrm{Ti}_{3} \mathrm{Al}$ phases. ${ }^{13)}$ The network $\mathrm{Ti}-\mathrm{Al}$ alloy region has an average grain size of $840 \mathrm{~nm}$, as shown in Fig. 6(a), and the dispersed pure $\mathrm{Ti}$ region has an average grain size of $21 \mu \mathrm{m}$. The $\mathrm{Ti} / \mathrm{Ti}-48 \mathrm{Al}$ harmonic-structured composite consists of a nano grain network region and a coarse-grain dispersed region, same as the harmonic-structured material reported in previous research. ${ }^{8-11)}$ Such a harmonic-structured composite is expected to exhibit good mechanical properties.

Figure 7 demonstrates nominal stress-strain curves from the tensile test of the $\mathrm{Ti} / \mathrm{Ti}-48 \mathrm{Al}$ harmonic-structured composite with various weight ratios; the compact consisting of only $\mathrm{Ti}-48 \mathrm{Al}$ is also shown. ${ }^{14)}$ The $0.2 \%$ proof stresses of the harmonic-structured composite with $11.1,12.5$ and 14.3 mass \% $\mathrm{Ti}-48 \mathrm{Al}$ are 450,520 and $560 \mathrm{MPa}$, respectively. The total elongation values for the harmonic-structured composite with $11.1,12.5$ and 14.3 mass $\% \mathrm{Ti}-48 \mathrm{Al}$ are $0.18,0.58$ and $0.35 \%$, respectively. On the other hand, the $0.2 \%$ stress and the total elongation of the compact consisting of only $\mathrm{Ti}-48 \mathrm{Al}$ are $350 \mathrm{MPa}$ and $0.25 \%$, respectively. ${ }^{14)}$ The averages of $0.2 \%$ proof stress for the harmonic-structured
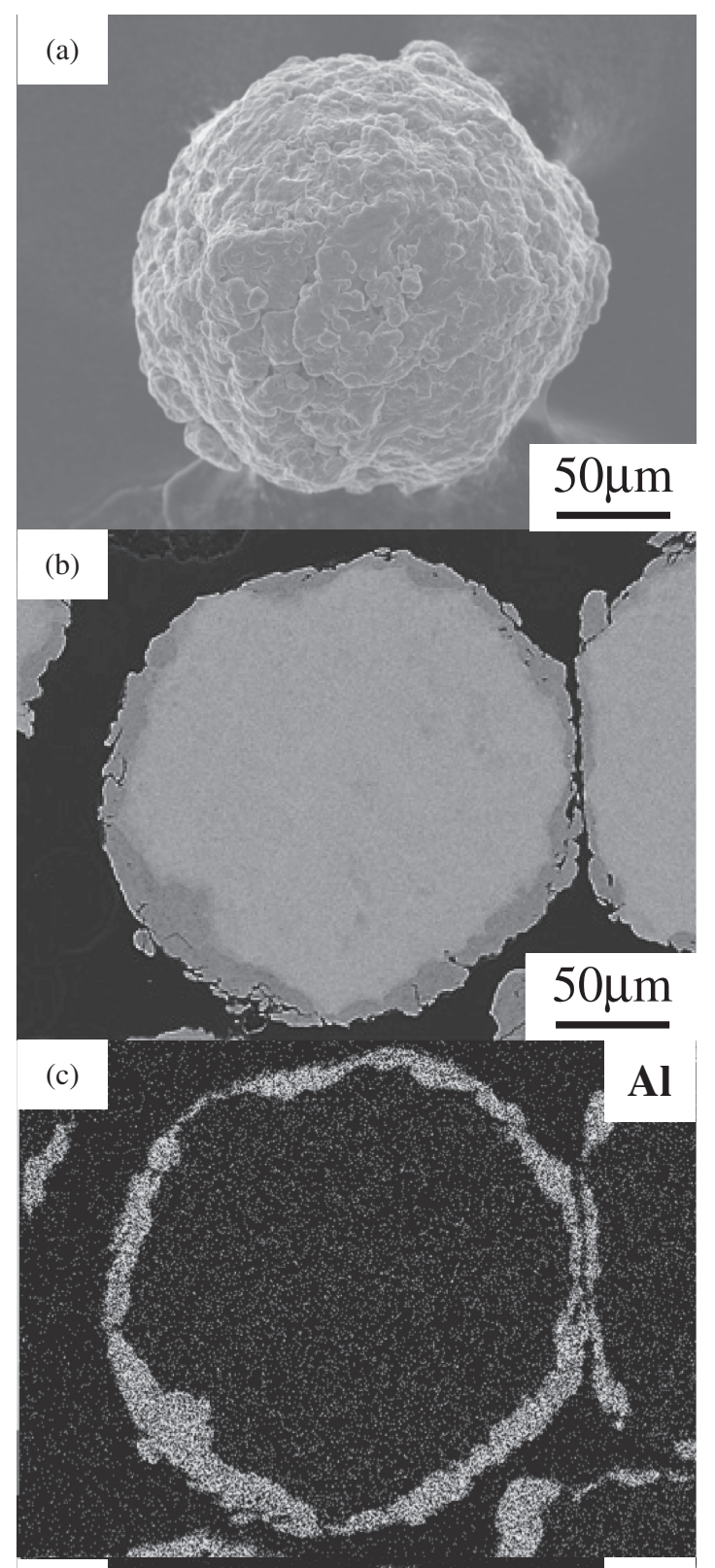

(d)
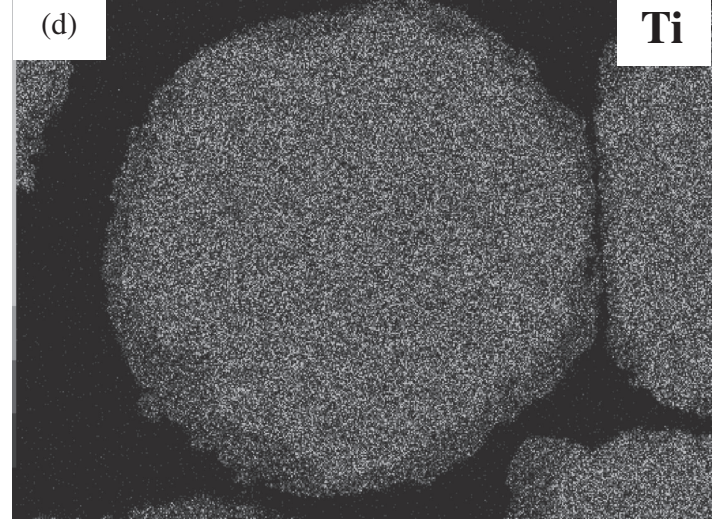

Fig. 2 SEM micrographs of the composite MM powder with Ti-48Al $(20.0 \mathrm{mass} \%)$. (a) and (b) are the appearance and the cross sectional image, respectively. (c) and (d) are EDS results for the distribution of $\mathrm{Al}$ and Ti element, respectively.

composite with $11.1,12.5$ and 14.3 mass $\%$ Ti-48Al are 506, 440 and $549 \mathrm{MPa}$, respectively. The averages of total elongation for the harmonic-structured composite with 11.1, 


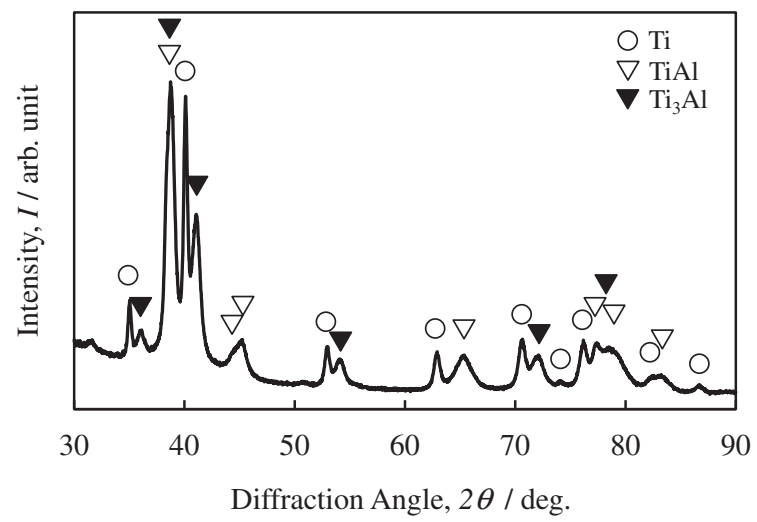

Fig. 3 XRD result for the composite MM powder with Ti-48Al (20.0 mass\%).

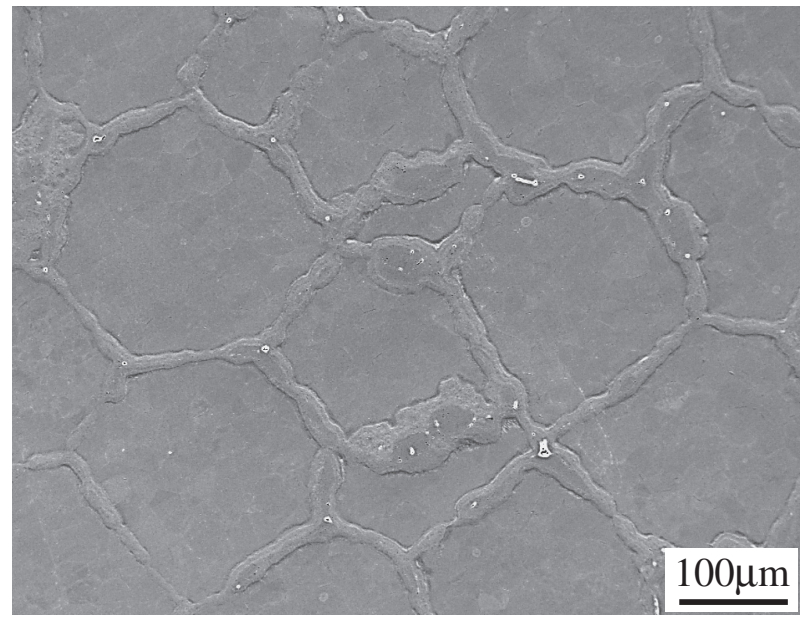

Fig. 4 SEM micrograph of the $\mathrm{Ti} / \mathrm{Ti}-48 \mathrm{Al}$ harmonic structured composite with the weight ratio of Ti-48Al (14.3 mass\%), sintered by SPS at $1073 \mathrm{~K}$ for $1.8 \mathrm{ks}$.

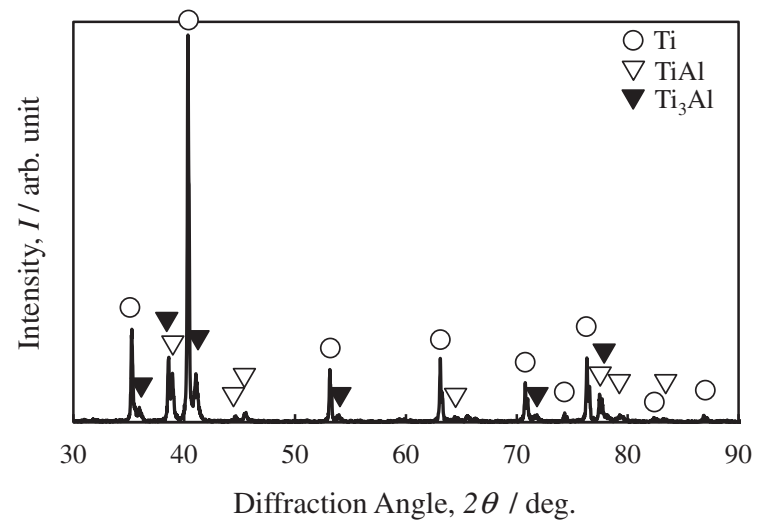

Fig. $5 \mathrm{XRD}$ result for the $\mathrm{Ti} / \mathrm{Ti}-48 \mathrm{Al}$ harmonic-structured composite with Ti-48Al (14.3 mass\%) shown in Fig. 4.

12.5 and 14.3 mass $\% \mathrm{Ti}-48 \mathrm{Al}$ are $0.22,0.47$ and $0.34 \%$, respectively. The standard deviations are $0.040,0.090$ and 0.015 , respectively. As a result, the harmonic- structured composites with $\mathrm{Ti}-48 \mathrm{Al}$ (12.5 and 14.3 mass $\%)$ indicate high strength and high elongation compared with the conventional Ti-48Al compact. The harmonic-structured composite having the middle weight ratio of $\mathrm{Ti}-48 \mathrm{Al}$
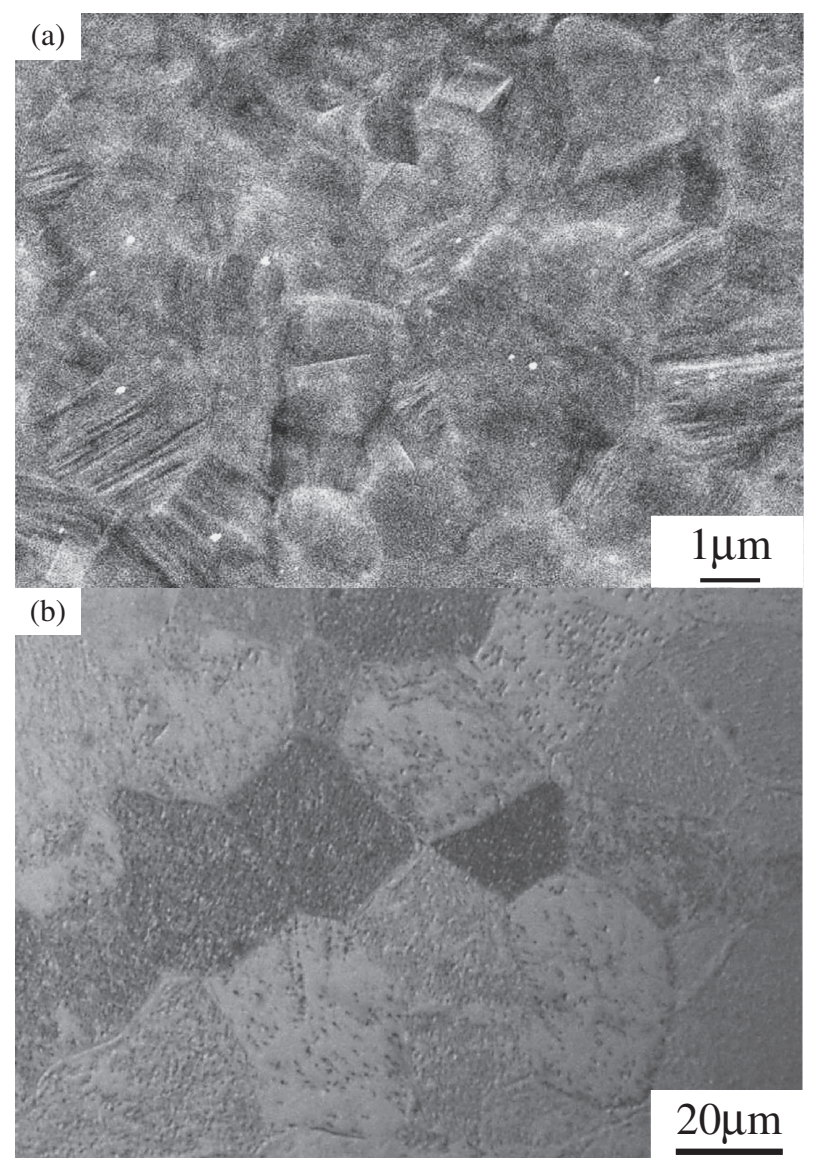

Fig. 6 (a) SEM and (b) OM micrographs of the network and dispersed region of the $\mathrm{Ti} / \mathrm{Ti}-48 \mathrm{Al}$ harmonic-structured composite with $\mathrm{Ti}-48 \mathrm{Al}$ (14.3 mass\%), respectively.

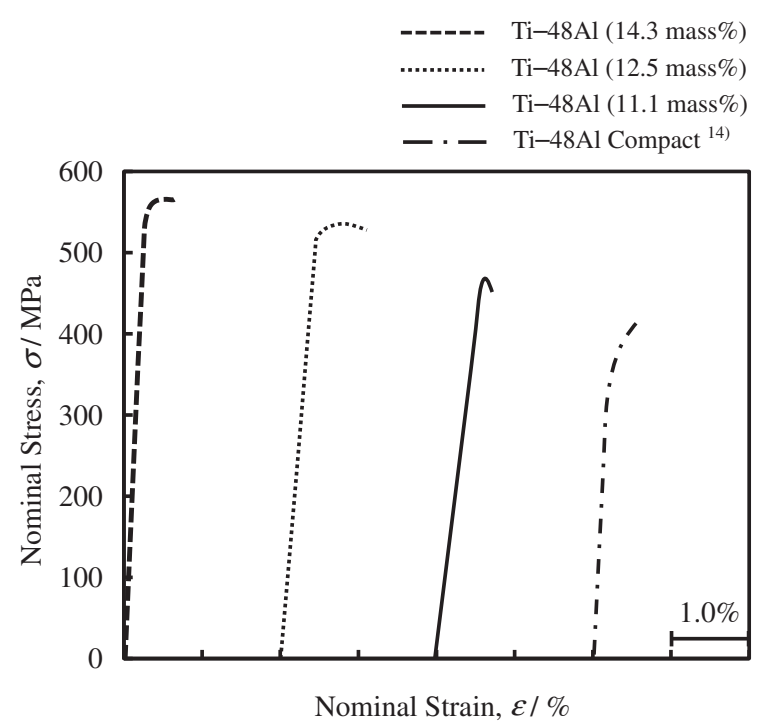

Fig. 7 Nominal stress-nominal strain curves of the Ti/Ti-48Al harmonicstructured composite with $\mathrm{Ti}-48 \mathrm{Al}$ (11.1 to 14.3 mass $\%$ ). Alternate long and short dash lines curve also shows the compact consisting of only Ti48Al alloy. ${ }^{14)}$

demonstrates the best elongation but low $0.2 \%$ proof stress, suggesting the existence of an optimal microstructure design. ${ }^{8)}$ Such a result indicates that a harmonic-structured composite of $\mathrm{Ti}$ and a $\mathrm{Ti}-\mathrm{Al}$ alloy could effectively improve the mechanical properties of a $\mathrm{Ti}-\mathrm{Al}$ alloy at room temper- 


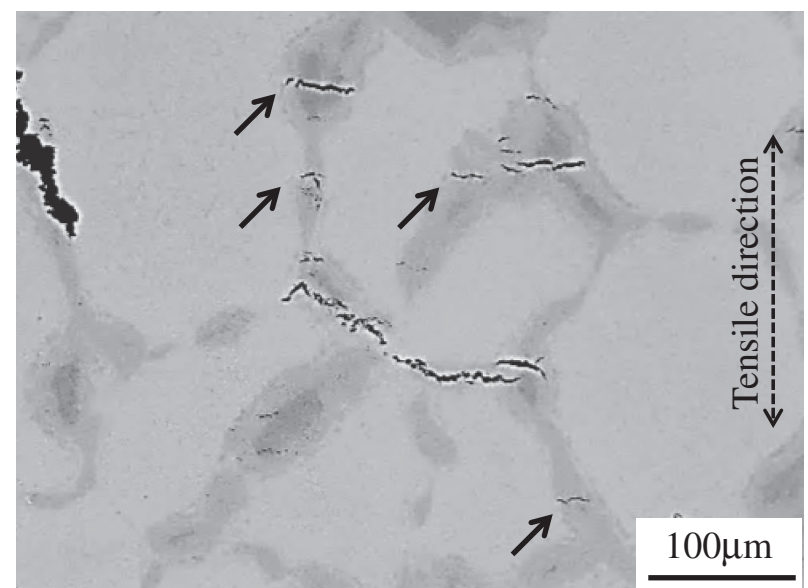

Fig. 8 SEM micrograph in the vicinity of the fracture surface after tensile test of $\mathrm{Ti} / \mathrm{Ti}-48 \mathrm{Al}$ harmonic-structured composite with $\mathrm{Ti}-48 \mathrm{Al}$ (14.3 $\operatorname{mass} \%)$.

ature. Figure 8 shows an SEM micrograph in the vicinity of the fracture surface after the tensile test. Some cracking is observed at the network region; thus, the fracture initiated at the network region and propagated there. However, some crack propagation was prevented by the dispersed region, as indicated by the arrows in Fig. 8. Therefore, the harmonicstructured composite can deform without a rapid fracture. Advanced ductility of the harmonic-structured materials is attributed to the obstruction of crack propagation by the dispersed region. ${ }^{11)}$

As mentioned above, the $\mathrm{Ti} / \mathrm{Ti}-48 \mathrm{Al}$ harmonic-structured composite demonstrates advanced mechanical properties at room temperature. To investigate its thermal stability, the harmonic-structured composite with 14.3 mass $\%$ Ti-48Al was annealed at 873,973 and $1073 \mathrm{~K}$ for $3.6 \mathrm{ks}$. The SEM micrograph and EDS results for the annealed harmonicstructured composite are shown in Fig. 9. As shown in the figure, the heat treatment leads to the stabilization of the harmonic-structured composite at high temperature. Figure 9(a) shows the harmonic structure in spite of the heat treatment at $1073 \mathrm{~K}$. Figures 9(b) and 9(c) indicate that the $\mathrm{Al}$ element is concentrated at the network region and that the Ti element is comparatively highly concentrated at the dispersed region. The XRD result for this material indicates that the phase composition is the same as that in the result shown in Fig. 5. Figure 10 shows the Vickers hardness test results for the $\mathrm{Ti}-48 \mathrm{Al}$ compact, the pure $\mathrm{Ti}$ compact, and the harmonic-structured composite before and after heat treatment. As the temperature increases, the hardness of the Ti-48Al compact and the pure Ti compact decreases to a lesser and to a greater extent, respectively. In contrast, the hardness of the harmonic-structured composite remains high hardness after the heat treatment in spite of the addition of 14.3 mass $\%$ of $\mathrm{Ti}-48 \mathrm{Al}$. This result suggests that the $\mathrm{Ti} / \mathrm{Ti}-$ 48Al harmonic-structured composite would exhibit good properties at high temperature.

\section{Conclusion}

A harmonic-structured composite with a network region of a $\mathrm{Ti}-\mathrm{Al}$ alloy and a dispersed region of pure titanium was

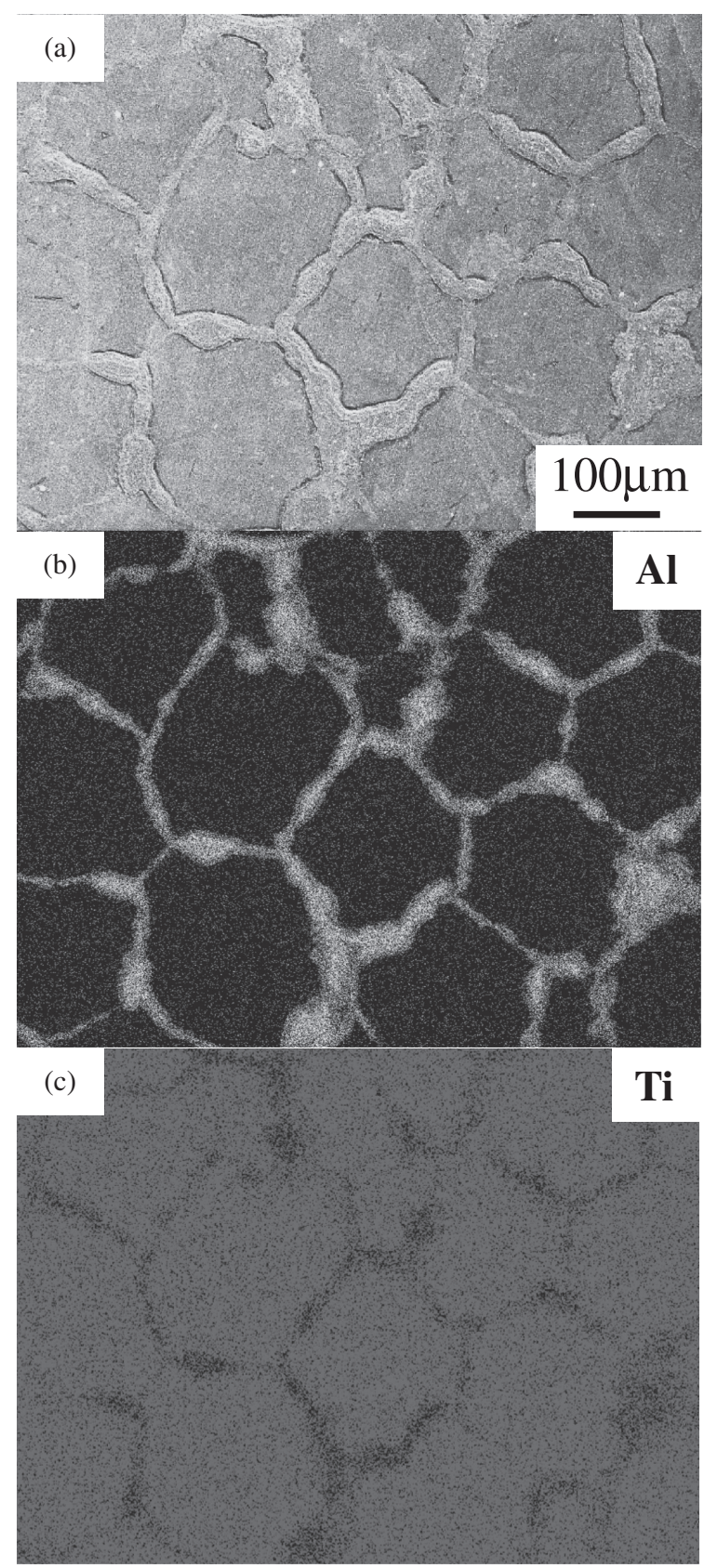

Fig. 9 (a) is SEM micrograph of the cross sectional image of the Ti/Ti48Al harmonic-structured composite with Ti-48Al (14.3 mass $\%)$ after annealing at $1073 \mathrm{~K}$ for $3.6 \mathrm{ks}$. (b) and (c) are EDS results for the distribution of $\mathrm{Al}$ and $\mathrm{Ti}$ elements of (a), respectively.

fabricated by a mechanical milling and spark plasma sintering. The microstructure and mechanical properties of the harmonic-structured composite were evaluated. The composite powder with a surface of the $\mathrm{Ti}-48$ at $\% \mathrm{Al}$ alloy and a middle region of pure titanium was produced by the mechanical milling. As this composite powder underwent spark plasma sintering, the harmonic-structured composite with a network region of a $\mathrm{Ti}-\mathrm{Al}$ alloy and a dispersed region of pure titanium was created. At room temperature, the harmonic-structured composite demonstrated high strength and advanced ductility as compared with the compact consisting of only $\mathrm{Ti}-48 \mathrm{at} \% \mathrm{Al}$. After heat treatment at $1073 \mathrm{~K}$, its hardness decreased to much lesser than of the pure Ti compact. 
Ti-48Al Compact

$\mathbb{N}$ Ti/Ti-48Al Harmonic Structured Composite

$\square$ Pure Ti Compact

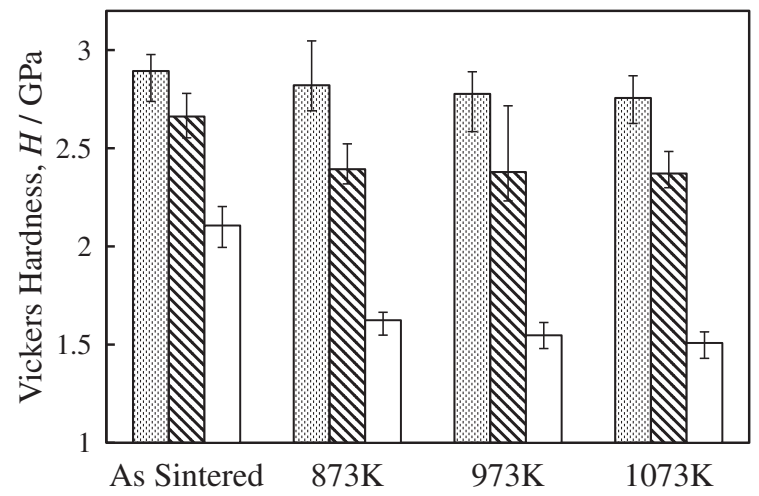

Fig. 10 Vickers hardness of the pure $\mathrm{Ti}$, Ti-48Al compact, and the $\mathrm{Ti} / \mathrm{Ti}-$ 48Al harmonic-structured composite with $\mathrm{Ti}-48 \mathrm{Al}(14.3 \mathrm{mass} \%)$ after annealing at various temperature.

\section{Acknowledgments}

This work was supported by grant-in-aid from Iketani Science and Technology Foundation and the support is gratefully appreciated.

\section{REFERENCES}

1) H. Jabbar, J.-P. Monchoux, M. Thomas and A. Couret: Acta Mater. 59 (2011) 7574-7585.

2) A. Couret, G. Molenat, J. Galy and M. Thomas: Intermatallics 16 (2008) 1134-1141.

3) X. Lu, X. B. He, B. Zhang, L. Zhang, X. H. Qu and Z. X. Guo: Intermatallics 17 (2009) 840-846.

4) H. A. Lipsitt, D. Shechtman and R. E. Schafrik: Metall. Trans. A 6A (1975) 1991-1996

5) Y. Liu, H. Li, S. Wang and H. Ye: J. Mater. Res. 24 (2009) 31653173.

6) E. Ma: Scr. Mater. 49 (2003) 663-668.

7) N. Tsuji, N. Kamikawa, R. Ueji, N. Takata, H. Koyama and D. Terada: ISIJ Int. 48 (2008) 1114-1121.

8) T. Sekiguchi, K. Ono, H. Fujiwara and K. Ameyama: Mater. Trans. 51 (2010) 39-45.

9) H. Fujiwara, R. Akada, A. Noro, Y. Yoshita and K. Ameyama: Mater. Trans. 49 (2008) 90-96.

10) H. Fujiwara, T. Sekiguchi and K. Ameyama: Int. J. Mater. Res. 100 (2009) 796-799.

11) A. Ueno, H. Fujiwara, M. Rifai, Z. Zhang and K. Ameyama: J. Soc. Mater. Sci. Jpn. 61 (2012) 686-691.

12) H. Mabuchi, N. Kiji, H. Tsuda and Y. Nakayama: J. Jpn. Soc. Powder Powder Met. 42 (1995) 1289-1294.

13) S. C. Huang and E. L. Hall: Metall. Trans. A 22A (1991) 427-439.

14) K. Kato, A. Matsumoto, Y. Nozaki and T. Ieki: J. Jpn. Soc. Powder Powder Met. 42 (1995) 1068-1072. 